\title{
Overview and first results of the Wind and Storms Experiment (WASTEX): a field campaign to observe the formation of gusts using a Doppler lidar
}

\author{
Florian Pantillon, Andreas Wieser, Bianca Adler, Ulrich Corsmeier, and Peter Knippertz
}

Institute of Meteorology and Climate Research, Karlsruhe Institute of Technology, Karlsruhe, Germany

Correspondence: Florian Pantillon (florian.pantillon@kit.edu)

Received: 7 February 2018 - Revised: 3 May 2018 - Accepted: 18 May 2018 - Published: 25 May 2018

\begin{abstract}
Wind gusts are responsible for most damages in winter storms over central Europe, but capturing their small scale and short duration is a challenge for both models and observations. This motivated the Wind and Storms Experiment (WASTEX) dedicated to investigate the formation of gusts during the passage of extratropical cyclones. The field campaign took place during the winter 2016-2017 on a former waste deposit located close to Karlsruhe in the Upper Rhine Valley in southwest Germany. Twelve extratropical cyclones were sampled during WASTEX with a Doppler lidar system performing vertical scans in the mean wind direction and complemented with a Doppler C-band radar and a $200 \mathrm{~m}$ instrumented tower. First results are provided here for the three most intense storms and include a potential sting jet, a unique direct observation of a convective gust and coherent boundary-layer structures of strong winds.
\end{abstract}

\section{Introduction}

Windstorms associated with low-pressure systems from the North Atlantic belong to the most destructive natural hazards for central Europe (Lamb and Frydendahl, 1991). During storms, most destructions arise from short-lived (typically a few seconds) but intense wind peaks known as gusts, which can substantially damage infrastructure and devastate forest areas (Klawa and Ulbrich, 2003). Due to their local and intermittent nature, wind gusts are not explicitly represented by numerical weather prediction and climate models, even at high resolution, which rely on subgrid-scale parameterizations. These are based on empirical models of boundarylayer turbulence (Panofsky et al., 1977) or physical assumptions on the downward transport of momentum by eddies (Brasseur, 2001) and by convective downdrafts (Nakamura et al., 1996). In addition, wind gusts are not well sampled by surface observation networks, whose spatial coverage is sparse and thus hinders model verification (Friederichs et al., 2009). These issues are challenges for both modelling and observing wind gusts.

The Wind and Storms Experiment (WASTEX) was conducted during the winter 2016/17 in Karlsruhe, southwest- ern Germany, to better understand the formation of wind gusts during the passage of storms. The key instrument of the field campaign was a Doppler lidar, which provides accurate wind observations along its beam with high spatial and temporal resolutions and within a range of several $\mathrm{km}$. Although Doppler lidars have been used to observe wind storms for several decades (Neiman et al., 1988), the number of field campaigns dedicated to gust observations is small. Recent technological developments have generalized the use of Doppler lidars to complement traditional measurement techniques, in particular for wind energy applications (e.g., Suomi et al., 2017). The approach presented here follows earlier work by Träumner et al. (2012), who observed the formation of devastating gusts in a forest area during a severe winter storm. In the framework of WASTEX, the formation of gusts in winter storms was systematically sampled during a whole season using a Doppler lidar as well as a Doppler radar and a $200 \mathrm{~m}$ instrumented tower located nearby.

The paper is structured as follows: Sect. 2 describes the instrumentation, Sect. 3 presents an overview of the field campaign, Sect. 4 details some selected observations and Sect. 5 gives conclusions and future research perspectives. 


\section{Instrumentation}

Gust-resolving wind measurements during winter storm events place very high demands on a lidar instrument. Detecting single structures embedded in the fast airflow requires high scan rates, short accumulation times and high power laser sources, especially since fronts often involve precipitation and are thus typically followed by clear air with very few scatterers. Therefore, the Lockheed Martin WindTracer HYB scanning Doppler lidar of the KITcube observation platform (Kalthoff et al., 2013) was deployed for WASTEX. The instrument is based on a $2.02 \mu \mathrm{m}$ Tm:LuAG laser with $4.5 \mathrm{~kW}$ peak power, $370 \mathrm{~ms}$ pulse duration and $500 \mathrm{~Hz}$ pulse rate, which fulfills these demands. A maximum of 120 range gates can be arranged along the beam from $350 \mathrm{~m}$ to $10 \mathrm{~km}$ distance. The measured wind velocities show no bias and have a typical uncorrelated noise of $0.15 \mathrm{~m} \mathrm{~s}^{-1}$ in the high signalto-noise range (Träumner et al., 2011). The laser beam can be directed by a tow axis scanner into the entire upper hemisphere with scan rates up to $20^{\circ}$ per second. Matlab routines allow processing of measured data in near real time and the automatic adaption of the instrument settings and scan strategies to the actual wind situation.

In order to measure gusts, a sophisticated measurement strategy consisting of plan-position-indicator (PPI) and range-height-indicator (RHI) scans was applied to the Doppler lidar. Every hour two PPI scans at 15 and $75^{\circ}$ elevation were performed and were then used to calculate the mean horizontal wind profile using the velocity-azimuth display (VAD) technique (Browning and Wexler, 1968). The PPI scans took about $2 \mathrm{~min}$ in total. During the remaining time continuous RHI scans between 0 and $15^{\circ}$ elevation angle were performed. The RHI scans were aligned along the mean wind direction, which was retrieved by the VAD technique and averaged over the lower $1000 \mathrm{~m}$, with the laser beam pointing towards the flow. In case the line of sight of the laser beam was obscured by an obstacle in the direction of the wind, the closest azimuth angle with an unobscured view down to $0^{\circ}$ elevation angle was chosen. Deviations were generally less than $5^{\circ}$. The azimuth and elevation scan speeds were $6^{\circ}$ per second for both RHI and PPI scans with an accumulation time of $100 \mathrm{~ms}$. The maximum measurement range was between 400 and $8000 \mathrm{~m}$ with a range resolution along the beam of $70 \mathrm{~m}$. The actual measurement range depended on the backscatter concentration in the atmosphere and varied strongly.

During WASTEX, the Doppler lidar was located on the top of an artificial hill and former waste deposit at a height of $158 \mathrm{~m}$ a.s.l. The hill spans over $600 \mathrm{~m}$ in the west-east direction and $450 \mathrm{~m}$ in the north-south direction and it tops the surrounding Karlsruhe harbour by $51 \mathrm{~m}$ (Fig. 1). The interpretation of lidar data is facilitated by observations from additional instruments located about $11 \mathrm{~km}$ to the northeast on the Campus North of KIT. A dual polarized C-Band Doppler radar is installed at a height of $148 \mathrm{~m}$ a.s.l. and $38 \mathrm{~m}$

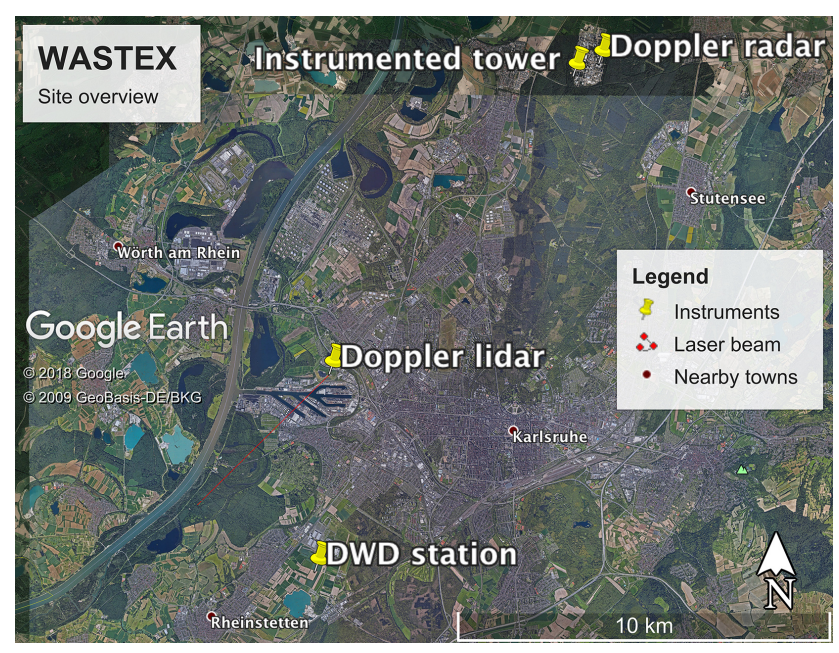

Figure 1. Illustration of the WASTEX site with the location of the different instruments and the DWD surface station (yellow pins). The Doppler lidar is located next to the Karlsruhe harbour and close to the Rhine river. The lidar beam is illustrated for a typical situation with southwesterly wind and a range of $5 \mathrm{~km}$ (red line).

above ground. Its main specifications are $5.3 \mathrm{~cm}$ wavelength, $250 \mathrm{~kW}$ peak pulse power, $4.2 \mathrm{~m}$ antenna diameter, $120 \mathrm{~km}$ range for volume scans and $500 \mathrm{~m}$ spatial resolution. The radar measures the reflectivity of the atmosphere, mainly caused by different kinds of hydrometeors, as well as their radial wind speed. It also provides derived values such as precipitation intensity, vertical liquid content, wind profiles and hydrometeor classification. Close to the radar, a $200 \mathrm{~m}$ instrumented meteorological tower has its base at $114 \mathrm{~m}$ a.s.l. and is located in a forest area with 20-to- $25 \mathrm{~m}$ high trees (Fig. 1; Kohler et al., 2018). In addition to air pressure, precipitation and radiation, the tower records wind speed at 11 levels, wind direction at 6 levels, temperature at 8 levels and dew point at 5 levels, all as $10 \mathrm{~min}$ mean values and between $2 \mathrm{~m}$ and $200 \mathrm{~m}$ a.g.l. Turbulence data are further measured with $20 \mathrm{~Hz}$ sampling rate at 4 levels, which allows the calculation of atmospheric stability in the lower boundary layer by using the dimensionless length parameter $z / L$ (Monin and Obukhov, 1954). The tower data thus enables to trace back periods of severe gusts to changes in stability and to mesoscale phenomena such as fronts, convective systems or cold pools.

\section{Overview of the field campaign}

The 2016-2017 winter was an active season for storms over southwestern Germany (black curve in Fig. 2). Altogether, 6 Intense Observations Periods (IOPs) were conducted and sampled 12 storms between mid-December 2016 and mid-March 2017 (Table 1). The field campaign started during Christmas time with the passage of storms Antje 


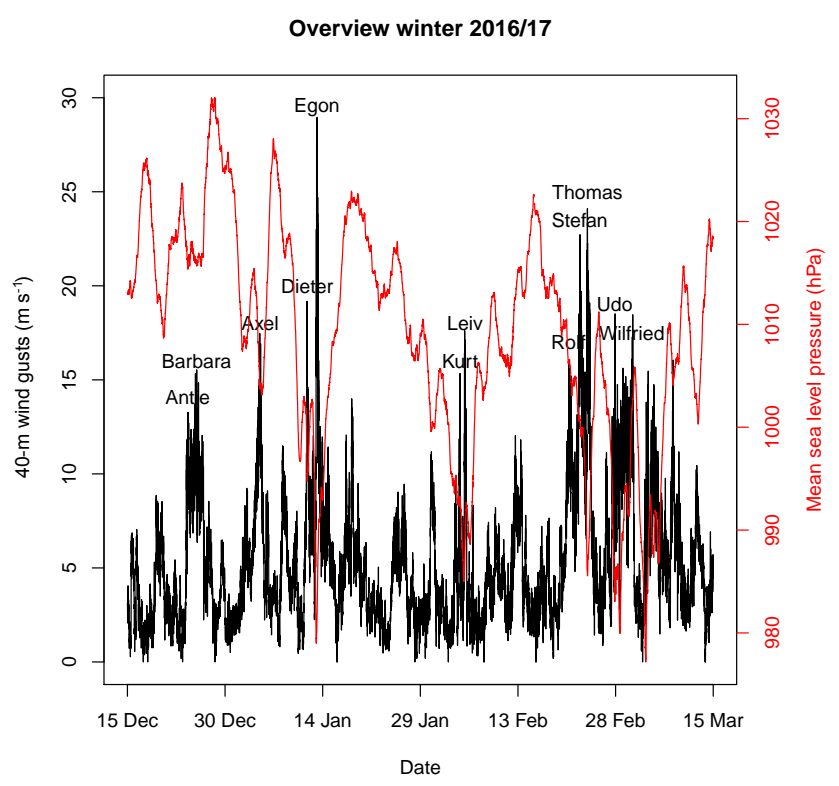

Figure 2. Overview of the $2016 / 2017$ winter: wind gust at $40 \mathrm{~m}$ a.g.l. (in $\mathrm{m} \mathrm{s}^{-1}$; black) and mean-sea-level pressure (in $\mathrm{hPa}$; red) recorded at the KIT instrumented tower (see Fig. 1 for the location). The $40 \mathrm{~m}$ a.g.l. level of the tower ( $154 \mathrm{~m}$ a.s.1.) is close to the height of the lidar (158 ma.s.l.). Storms sampled during the IOPs are labelled.

and Barbara ${ }^{1}$ on 24 and 25 December (IOP1) and was discontinued after a storm series that ended with Wilfried on 2 March (IOP6). Most IOPs sampled two or more consecutive storms separated by periods dominated by high-pressure systems (red curve in Fig. 2). This tendency of extratropical cyclones to cluster is due to favourable conditions in the large-scale dynamics (Pinto et al., 2014). It facilitates the planning of observations, as the track and intensity of storms can be predicted 2-4 days in advance only (Pantillon et al., 2017). It also ensures the stability of lidar measurements by avoiding the instrument to be switched on and off between each and every storm.

A striking peak was recorded during the passage of storm Egon on 13 January 2017 (IOP3), when wind gusts at $40 \mathrm{~m}$ a.g.l. reached $29.0 \mathrm{~m} \mathrm{~s}^{-1}$ (Fig. 2). Further peak gusts were recorded during the two consecutive storms Stefan and Thomas on 22 and 23 February 2017 (IOP5) with 22.7 and $24.1 \mathrm{~m} \mathrm{~s}^{-1}$, respectively. These measurements from the instrumented tower at $40 \mathrm{~m}$ height in a forest area can be compared to reference observations at the Deutscher Wetterdienst (DWD) surface station in Rheinstetten, distant by about $15 \mathrm{~km}$ and located closer to the lidar beam (Fig. 1). Daily maximum $10 \mathrm{~m}$ wind gusts highlight the same three storms Egon, Stefan and Thomas, which reached 26.3, 20.4 and $24.1 \mathrm{~m} \mathrm{~s}^{-1}$, respectively (Table 1). Differences in absolute

\footnotetext{
${ }^{1}$ The storm named Antje by the Free University of Berlin was baptized Barbara by Met Éireann and the UK Met Office, which can be misleading.
}

Table 1. List of storms observed during Intense Observation Periods. Names are those given by the Free University of Berlin and alternative names given by Met Éireann and the UK Met Office are added in brackets when available. Gusts are daily maxima recorded at the DWD surface station (see Fig. 1 for the location). The 3 selected storms are marked in bold.

\begin{tabular}{lllc}
\hline IOP & Date & Name & $\begin{array}{c}\text { Gust } \\
\left(\mathrm{m} \mathrm{s}^{-1}\right)\end{array}$ \\
\hline IOP1 & 24 Dec 2016 & Antje (Barbara) & 13.2 \\
IOP1 & 25 Dec 2016 & Barbara (Conor) & 15.8 \\
IOP2 & 4 Jan 2017 & Axel & 15.6 \\
IOP3 & 11 Jan 2017 & Dieter & 17.1 \\
IOP3 & 13 Jan 2017 & Egon & $\mathbf{2 6 . 3}$ \\
IOP4 & 3 Feb 2017 & Kurt & 13.8 \\
IOP4 & 4 Feb 2017 & Leiv & 17.2 \\
IOP5 & 20 Feb 2017 & Rolf & 13.8 \\
IOP5 & 22 Feb 2017 & Stefan & 20.4 \\
IOP5 & 23 Feb 2017 & Thomas (Doris) & $\mathbf{2 4 . 1}$ \\
IOP6 & 27 Feb 2017 & Udo & $\mathbf{2 6 . 4}$ \\
IOP6 & 2 Mar 2017 & Wilfried & 17.0 \\
\hline
\end{tabular}

numbers between the two datasets are due to different measurement heights and surrounding surfaces but also to different locations, as gusts are intermittent and affected by local processes. Surprisingly, the strongest gust of the season at the DWD station of $26.4 \mathrm{~m} \mathrm{~s}^{-1}$ was recorded during the passage of storm Udo on 27 February 2017, whereas gusts did not exceed $18.2 \mathrm{~m} \mathrm{~s}^{-1}$ at the instrumented tower on that day (Fig. 2). As discussed in the next section, this event involved intense convection and thus the observed gusts were very sensitive to the precise location of the measuring sites.

For comparison, highest speeds in daily maximum wind gusts recorded at the DWD station - available from 1 November 2008 until 31 December 2017 - were reached by winter storms Xynthia on 28 February $2010\left(31.6 \mathrm{~m} \mathrm{~s}^{-1}\right)$ and Quinten on 10 February $2009\left(28.6 \mathrm{~m} \mathrm{~s}^{-1}\right)$, as well as by two convective storms on 20 June and 6 August 2013 (31.3 and $30.8 \mathrm{~m} \mathrm{~s}^{-1}$, respectively). These extreme values are directly followed by storms Udo and Egon, while storm Thomas was less severe but still exceeded the 99.5th percentile in records for the November 2008-December 2017 period $\left(23.3 \mathrm{~m} \mathrm{~s}^{-1}\right)$. The three intense events are selected to illustrate examples of lidar observations using RHI scans in the next section.

\section{Selected intense observation periods}

Storm Egon was a small and fast-moving cyclone that quickly intensified over the English Channel before producing extreme wind gusts from northern France to western Germany on 12-13 January 2017. The strongest gust reached $80 \mathrm{kt}\left(41.2 \mathrm{~m} \mathrm{~s}^{-1}\right)$ and was recorded on the Weinbiet, a 553-m mountain top in the Palatine Forest located about $40 \mathrm{~km}$ only to the north of the WASTEX site. The intensity 
(a) Satellite and SYNOP observations

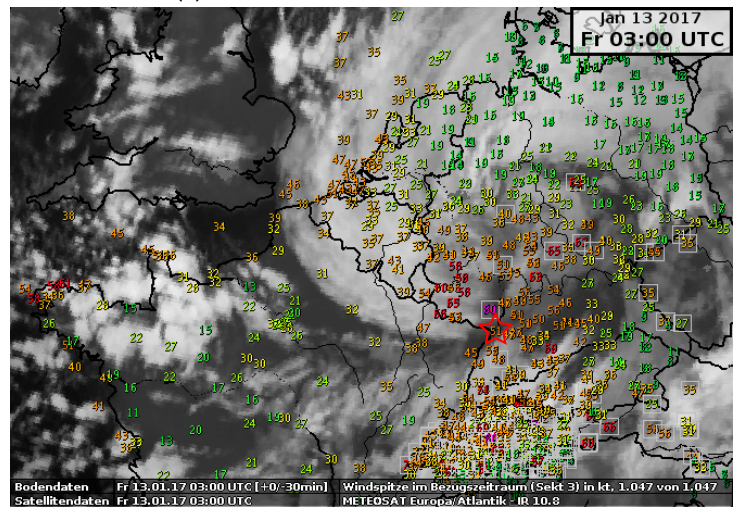

(b) Lidar observations

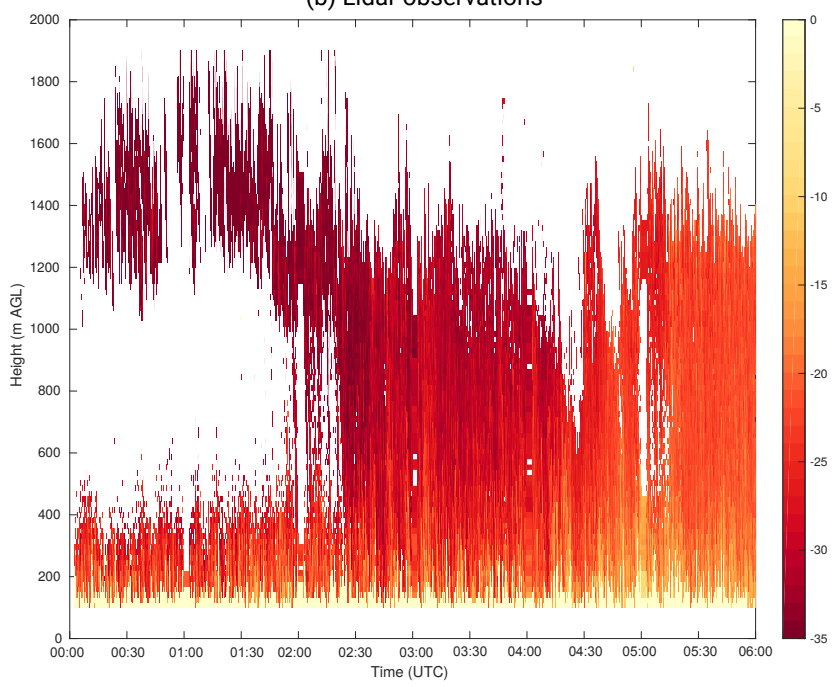

Figure 3. Observations of storm Egon on 13 January 2017 (IOP3): infrared satellite imagery and gusts reported by SYNOP stations at 03:00 UTC (in kt; a) and time-height plot of lidar radial velocity measured with $14 \pm 0.5^{\circ}$ elevation in the west-southwest direction from 00:00 to 06:00 UTC (in $\mathrm{m} \mathrm{s}^{-1}$; b). The red star in (a) shows the location of the WASTEX site.

of wind gusts and their occurrence at the tip of the cloud head (Fig. 3a) suggest that they may be due to a sting jet, a mesoscale feature present in some intense Shapiro-Keyser cyclones (Browning, 2004). As is the case for sting jets, the strongest gusts of Egon occurred southwest of the cyclone centre in the region of the bent-back warm front (Fig. 3a). Unfortunately, precipitation occurred earlier along the cold front and hindered lidar observations for several hours due to the wet removal of aerosols, which are crucial to backscatter the laser beam (Fig. 3b). Subsidence could also have played a role by bringing cleaner air down. However, the lidar range later increased again with the aerosol concentration and allowed observing extreme winds reaching $35 \mathrm{~m} \mathrm{~s}^{-1}$ across the boundary layer around 02:30 UTC on 13 January. These observations coincide with strong surface gusts and would be unprecedented if they were indeed related to a sting jet. (a) Surface chart

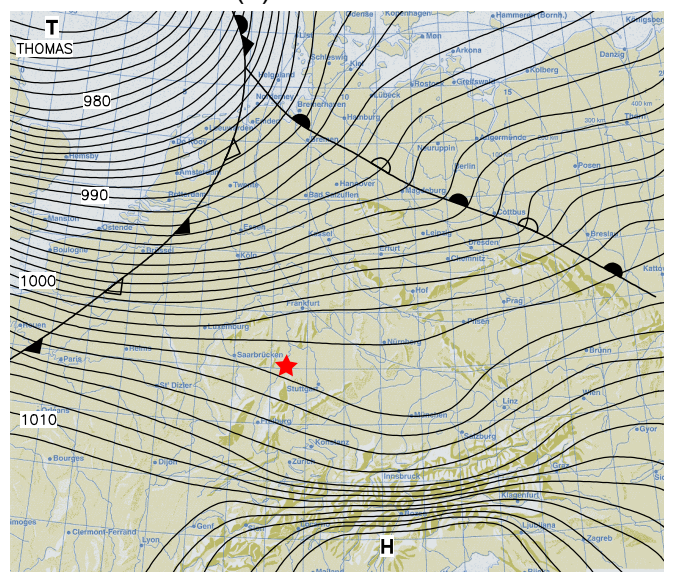

(b) Lidar observations

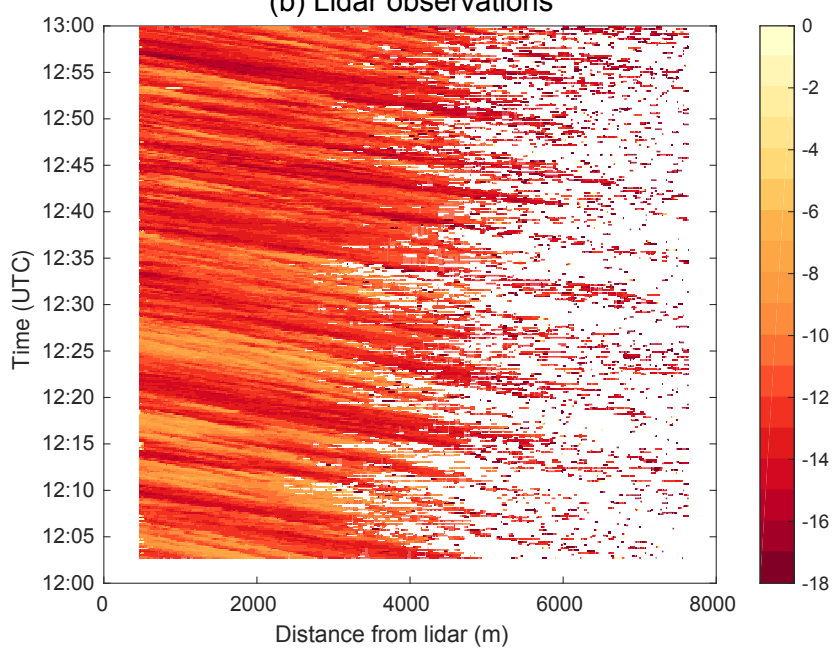

Figure 4. Observations of storm Thomas on 23 February 2017 (IOP5): surface chart adapted from the Berliner Wetterkarte at 12:00 UTC (a) and time-distance plot of lidar radial velocity measured at $100 \mathrm{~m}$ a.g.l. and corrected for the elevation angle in the southwest direction from 12:00 to 13:00 UTC (in $\mathrm{m} \mathrm{s}^{-1}$; b). The red star in (a) shows the location of the WASTEX site.

Storm Thomas ${ }^{2}$ was a larger storm that hit northern Europe and in particular Ireland and the UK on 23 February 2017. On the WASTEX site, the strongest gusts were recorded during the afternoon in the warm sector of the cyclone, which was centered over the North Sea at that time (Fig. 4a). Thanks to the combination of warm advection and cloud-free sky, the $2 \mathrm{~m}$ temperature recorded at the DWD station reached an unusual high for the season of $18.4^{\circ} \mathrm{C}$. Good atmospheric conditions for the lidar allowed observing coherent structures of strong southwesterly winds in the boundary layer (stripes in Fig. 4b). Structures of strong winds were previously observed with a similar experimental design during the passage of storm Xynthia and they were shown to

\footnotetext{
${ }^{2}$ Baptized Doris by Met Éireann and the UK Met Office.
} 
produce damages at a forest edge close to Karlsruhe (Träumner et al., 2012).

Storm Udo was part of a storm series that affected Europe in late February and early March 2017. It formed on 27 February over the North Sea as a secondary cyclone of another storm ${ }^{3}$ that hit Ireland on the previous day. Strong gusts covered a region from the Benelux states to Switzerland during the passage of Udo and were related to convection embedded in the cold front. Convection can transport momentum from higher levels to the surface and result in the most extreme gusts in winter storms, as highlighted during storm Kyrill on 18 January 2017 (Fink et al., 2009). This was also the case for Udo. Radar observations reveal the presence of new cells below $3000 \mathrm{~m}$ height developing directly westward of the WASTEX site at the arrival of convection embedded in the cold front (Fig. 5a). High rain intensities during the passage of the cold front of Udo reduced the lidar performance and the measurement range dropped from about 5 to $2 \mathrm{~km}$. However, lidar observations at that time show a pillar of strong south-southwesterly winds stretching across the boundary layer and apparently reaching the surface (Fig. 5b). The timing of these winds matches both the arrival of convection and the extreme gust record at the DWD station (Table 1). Considering the local and intermittent nature of convective gusts, such a direct observation is unique.

\section{Conclusions and perspectives}

The WASTEX field campaign was dedicated to the observation of wind gusts in winter storms using a Doppler lidar. Six IOPs encompassed twelve storms - with most of them occurring in clusters - during the active winter season 20162017. First results are presented here for the three most intense storms. Extreme gusts were recorded during the two storms Egon on 13 January and Udo on 27 February 2017. The mesoscale structure of Egon included a possible sting jet and appears unprecedented in the region, while the cold front of Udo involved embedded convection and allowed unique observations of a convective gust. Finally, coherent boundary-layer structures were observed in the warm sector of storm Thomas on 23 February 2017. These three examples highlight different processes responsible for the formation of wind gusts among winter storms that were sampled during the field campaign.

The analysis of campaign data is ongoing and observations are combined with three-dimensional model data to better understand the formation of gusts during the observed storms. Current work includes a detailed examination of coherent structures during the passage of storm Thomas in relation with turbulence driven by both local stability and background wind shear measured at the instrumented tower. A careful dynamical analysis of storm Egon based on mesoscale simulations is also ongoing to investigate the

\footnotetext{
${ }^{3}$ Baptized Ewan by Met Éireann and the UK Met Office
}

(a) Radar observation

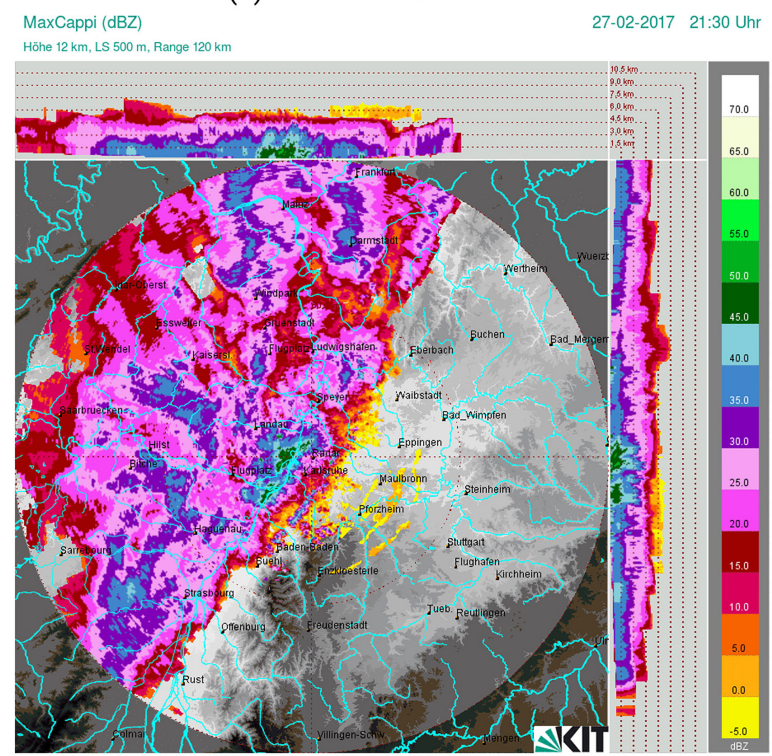

(b) Lidar observation

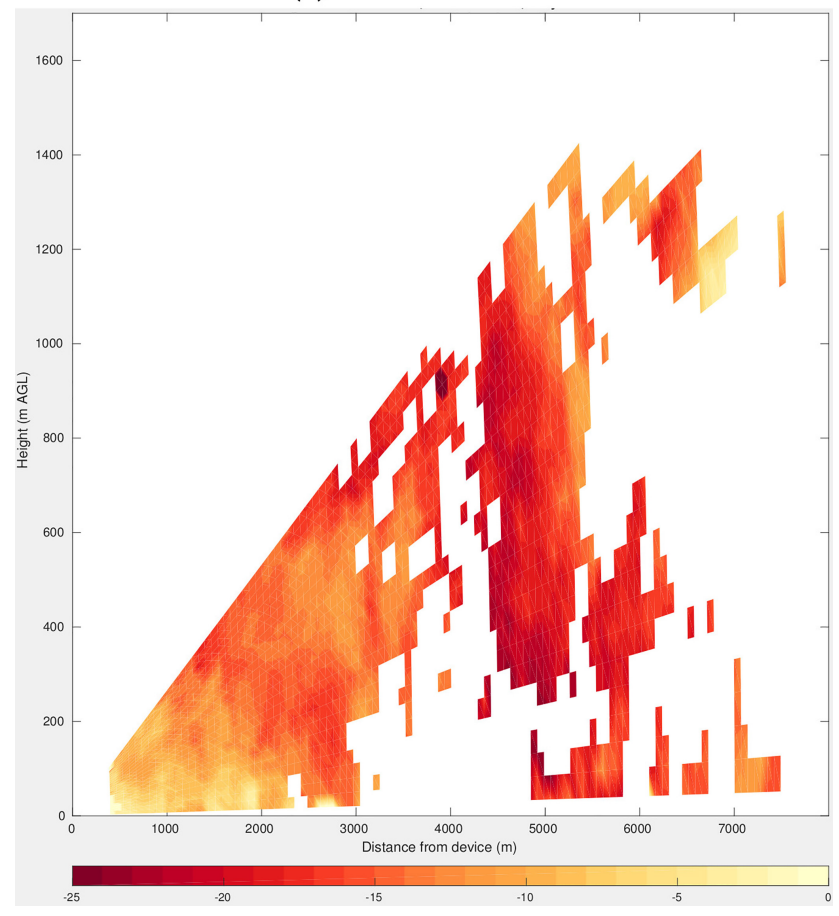

Figure 5. Observations of storm Udo on 27 February 2017 (IOP6): precipitation intensity from a radar volume scan displayed as vertical and horizontal projection of maximum reflectivity at 20:30 UTC (MaxCappi in $\mathrm{dBZ}$; a) and snapshot of lidar radial velocity in the south-southwest direction at 20:31:24 UTC (in $\mathrm{m} \mathrm{s}^{-1}$; b).

hypothesized presence of a sting jet. Future work will extend the results presented here for three storms to additional cases sampled during the field campaign. The potential of the Doppler radar will further be explored to complement the Doppler lidar during precipitation. The representation of 
gusts and boundary-layer momentum mixing will finally be assessed in operational forecasts - which rely on a subgridscale parameterization - as well as in large-eddy simulations, which should be able to explicitly resolve at least the largest wind structures (Heinze et al., 2017). Observations acquired during WASTEX have potential to offer a reference for a physically-based representation of wind gusts in numerical weather prediction and climate models.

Data availability. Lidar observations are available on request to the corresponding author.

Competing interests. The authors declare that they have no conflict of interest.

Special issue statement. This article is part of the special issue "17th EMS Annual Meeting: European Conference for Applied Meteorology and Climatology 2017”. It is a result of the EMS Annual Meeting: European Conference for Applied Meteorology and Climatology 2017, Dublin, Ireland, 4-8 September 2017.

Acknowledgements. The authors thank the City of Karlsruhe for hosting the Doppler lidar on the measurement site, Pia Bogert and Melissa Körlin for processing the campaign data, and two anonymous reviewers for comments that helped improving the original manuscript. Deutscher Wetterdienst (DWD) is acknowledged for providing surface station data, Meteosat for providing satellite observations, Berliner Wetterkarte for providing surface charts and Jan Handwerker for providing radar observations. The research leading to these results has been done within the subproject C5 "Forecast uncertainty for peak surface gusts associated with European cold-season cyclones" of the Transregional Collaborative Research Center SFB/TRR 165 "Waves to Weather" funded by the German Research Foundation (DFG).

The article processing charges for this open-access publication were covered by a Research

Centre of the Helmholtz Association.

Edited by: Sabrina Wahl

Reviewed by: two anonymous referees

\section{References}

Brasseur, O.: Development and Application of a Physical Approach to Estimating Wind Gusts, Mon. Weather Rev., 129, 5-25, https://doi.org/10.1175/15200493(2001)129<0005:DAAOAP>2.0.CO;2, 2001.

Browning, K. A.: The sting at the end of the tail: Damaging winds associated with extratropical cyclones, Q. J. Roy. Meteorol. Soc., 130, 375-399, https://doi.org/10.1256/qj.02.143, 2004.

Browning, K. A. and Wexler, R.: The determination of kinematic properties of a wind field using Doppler radar, J.
Appl. Meteorol., 7, 105-113, https://doi.org/10.1175/15200450(1968)007<0105:TDOKPO>2.0.CO;2, 1968.

Fink, A. H., Brücher, T., Ermert, V., Krüger, A., and Pinto, J. G.: The European storm Kyrill in January 2007: synoptic evolution, meteorological impacts and some considerations with respect to climate change, Nat. Hazards Earth Syst. Sci., 9, 405-423, https://doi.org/10.5194/nhess-9-405-2009, 2009.

Friederichs, P., Göber, M., Bentzien, S., Lenz, A., and Krampitz, R.: A probabilistic analysis of wind gusts using extreme value statistics, Meteorol. Z., 18, 615-629, https://doi.org/10.1127/09412948/2009/0413, 2009.

Heinze, R., Dipankar, A., Henken, C., Moseley, C., Sourdeval, O., Trömel, S., Xie, X., Adamidis, P., Ament, F., Baars, H., Barthlott, C., Behrendt, A., Blahak, U., Bley, S., Brdar, S., Brueck, M., Crewell, S., Deneke, H., Di Girolamo, P., Evaristo, R., Fischer, J., Frank, C., Friederichs, P., Göcke, T., Gorges, K., Hande, L., Hanke, M., Hansen, A., Hege, H.-C., Hoose, C., Jahns, T., Kalthoff, N., Klocke, D., Kneifel, S., Knippertz, P., Kuhn, A., van Laar, T., Macke, A., Maurer, V., Mayer, B., Meyer, C., Muppa, S., Neggers, R., Orlandi, E., Pantillon, F., Pospichal, B., Röber, N., Scheck, L., Seifert, A., Seifert, P., Senf, F., Siligam, P., Simmer, C., Steinke, S., Stevens, B., Wapler, K., Weniger, M., Wulfmeyer, V., Zängl, G., Zhang, D., and Quaas, J.: Large-eddy simulations over Germany using ICON: a comprehensive evaluation, Q. J. Roy. Meteorol. Soc., 143, 69-100, https://doi.org/10.1002/qj.2947, 2017.

Kalthoff, N., Adler, B., Wieser, A., Kohler, M., Träumner, K., Handwerker, J., Corsmeier, U., Khodayar, S., Lambert, D., Kopmann, A., Kunka, N., Dick, G., Ramatschi, M., Wickert, J., and Kottmeier, C.: KITcube - a mobile observation platform for convection studies deployed during HyMeX, Meteorol. Z., 22, 633647, https://doi.org/10.1127/0941-2948/2013/0542, 2013.

Klawa, M. and Ulbrich, U.: A model for the estimation of storm losses and the identification of severe winter storms in Germany, Nat. Hazards Earth Syst. Sci., 3, 725-732, https://doi.org/10.5194/nhess-3-725-2003, 2003.

Kohler, M., Metzger, J., and Kalthoff, N.: Trends in temperature and wind speed from 40 years of observations at a 200-m high meteorological tower in Southwest Germany, Int. J. Climatol., 38, 23-34, https://doi.org/10.1002/joc.5157, 2018.

Lamb, H. H. and Frydendahl, K.: Historic storms of the North Sea, British Isles and Northwest Europe, Cambridge University Press, Cambridge, England, 1991.

Monin, A. and Obukhov, A.: Basic Laws of Turbulent Mixing in the Surface Layer of the Atmosphere, Contrib. Geophys. Inst. Acad. Sci. USSR, 151, 163-187, 1954.

Nakamura, K., Kershaw, R., and Gait, N.: Prediction of near-surface gusts generated by deep convection, Meteorol. Appl., 3, 157167, https://doi.org/10.1002/met.5060030206, 1996.

Neiman, P. J., Hardesty, R. M., Shapiro, M. A., and Cupp, R. E.: Doppler Lidar Observations of a Downslope Windstorm, Mon. Weather Rev., 116, 2265-2275, https://doi.org/10.1175/15200493(1988)116<2265:DLOOAD>2.0.CO;2, 1988.

Panofsky, H. A., Tennekes, H., Lenschow, D. H., and Wyngaard, J. C.: The characteristics of turbulent velocity components in the surface layer under convective conditions, Bound.-Lay. Meteorol., 11, 355-361, https://doi.org/10.1007/BF02186086, 1977.

Pantillon, F., Knippertz, P., and Corsmeier, U.: Revisiting the synoptic-scale predictability of severe European winter storms 
using ECMWF ensemble reforecasts, Nat. Hazards Earth Syst. Sci., 17, 1795-1810, https://doi.org/10.5194/nhess-171795-2017, 2017.

Pinto, J. G., Gómara, I., Masato, G., Dacre, H. F., Woollings, T., and Caballero, R.: Large-scale dynamics associated with clustering of extratropical cyclones affecting Western Europe, J. Geophys. Res.-Atmos., 119, 13704-13719, https://doi.org/10.1002/2014JD022305, 2014.

Suomi, I., Gryning, S.-E., O'Connor, E. J., and Vihma, T.: Methodology for obtaining wind gusts using Doppler lidar, Q. J. Roy. Meteorol. Soc., 143, 2061-2072, https://doi.org/10.1002/qj.3059, 2017.
Träumner, K., Kottmeier, C., Corsmeier, U., and Wieser, A.: Convective Boundary-Layer Entrainment: Short Review and Progress using Doppler Lidar, Bound.-Lay. Meteorol., 141, 369391, https://doi.org/10.1007/s10546-011-9657-6, 2011.

Träumner, K., Wieser, A., Ruck, B., Frank, C., Röhner, L., and Kottmeier, C.: The suitability of Doppler lidar for characterizing the wind field above forest edges, Forestry, 85, 399-411, https://doi.org/10.1093/forestry/cps038, 2012. 